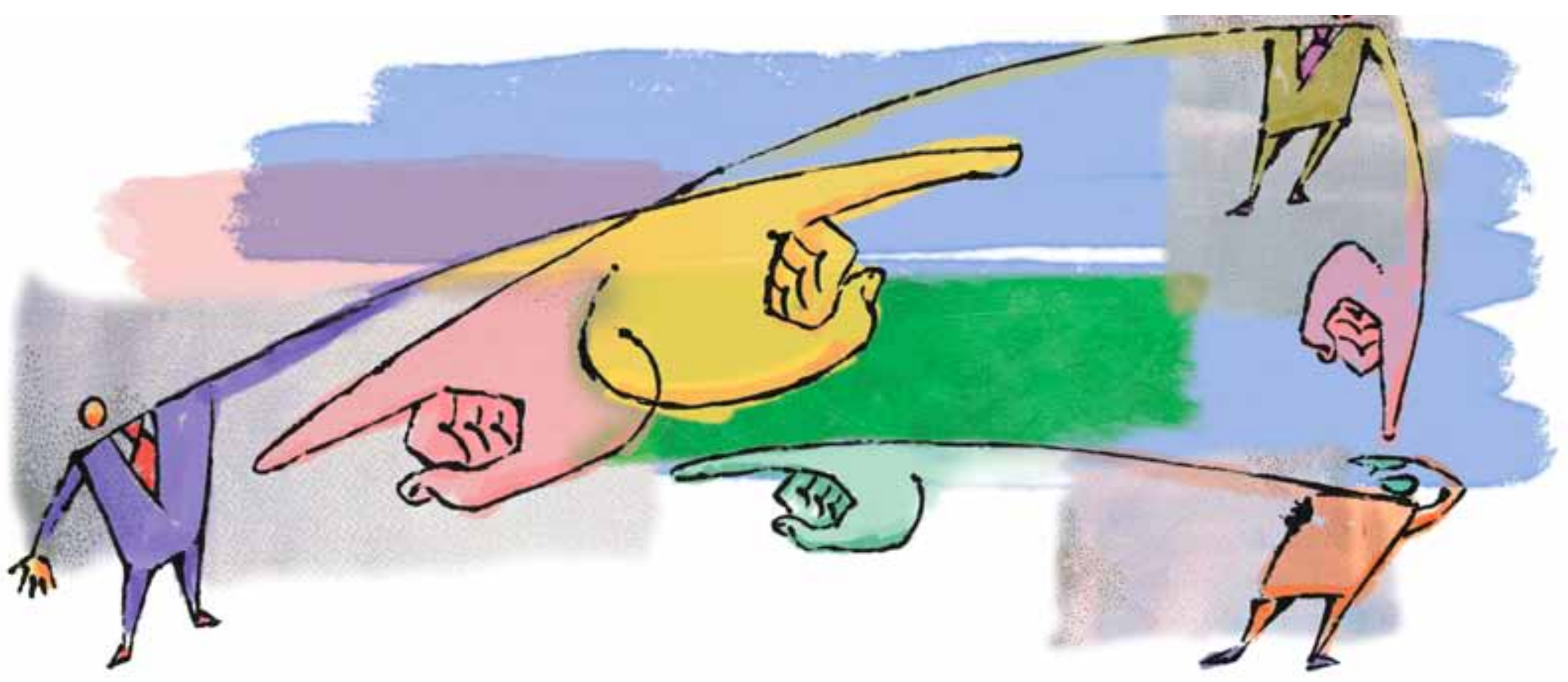

\title{
Institucionalidad, ética y desarrollo: legalidad versus legitimidad
}

Por Pablo González* Ph.D. en Economia, Universidad de Texas A\&tM, Estados Unidos. Académico UAH y Marcela Perticará, Ph.D. en Economía, Universidad de Texas A\&tM, Estados Unidos y Académica UAH

Por ejemplo en el año 2005, la policía era 列 Los paises con menores indices de corrupen la opinión pública de que el problema es más generalizado de lo que se ve, puede hacernos cambiar de opinión sobre esta idea de un Chile tan pulcro. Más aún, existe un riesgo-y esto ha sido destacado en numerosos medios internacionales-, de que estos escándalos son a la vez una oportunidad, pero mal manejados pueden perjudicar imagen de la institucionalidad del pais? Al analizar los datos del Barómetro Globa de Corrupción de Transparencia Internacional (htet./Www. Transparency.org/gcb2013), se distingue que las percepciones del públith útima medición disponible corresponde a año 2013) versus la vigente casi 10 años atrás (año 2005) son más pesimistas pero mostraban un patrón de desconfianza particularmente adversos al sistema politico. Los partidos politicos, parlamento, sistem judicial, ocupan -tanto en el año 2005 como en el año 2013-, los primeros tres lugares en el ranking de instituciones más corruptas

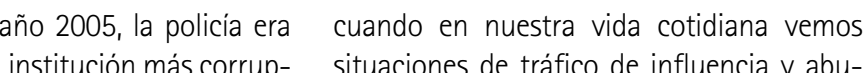
ranking 2013 es el sector so de poder, que culturalmente parecen ser Dado. El público cambió radicalmente su aceptadas en todos los niveles sociecopinión sobre el grado de corrupción exis- nómicos y en las situaciones más diversas tente en cinco sectores: sistema educativo, Desde "apitutarse" para lograr ingresar un instituciones religiosas, instituciones mé- niño a un colegio determinado, hasta las dicas y de salud el sector empresarial y los altas tasas de evasión que se registran en medios de comunicacion. Para estos grupos el Transantiago. Ciertamente no creemos a fracción de personas que las encuentra sea correcto generalizar y afirmar que tocorruptas o extremadamente corruptas dos somos laxos en nuestra decencia, pero cambio entre 45 y 20 puntos porcentuales. claramente se ha producido en los uiltimos El cambio mayor se da para el sistema edu- años, un deterioro de la probidad media de cativo, seguido de las instituciones religiosas chileno tipo. Las mismas estadisticas del y el sistema de salud (ver Grafico 1). Barometro de Corrupcion de Transparencia Cuando uno repasa la lista de escándalos Internacional lo muestran: si en el año 2005 qu (colusión en el sector farmacios y en el do un soborno para obtener a aún segace producción de pollos caso Penta y Caval, más recientemente) uno no puede sino ciende al 10\%. Es la cultura del fin justifica Toconocer la capacidad del instrumento de los medios. Más aún, el 750 de la gente que Transparencia Internacional para medir la declarò haberlo pagado señala que lo hizo para "acelerar un trámite" o para "asegurarEntonces, no es que la desconfianza ac- se que cierto servicio le fuera provisto". № tual de la ciudadania frente al sector privado por nada, Chile ocupa orgullosamente el y pubbico no tenga fundamentos. Lo que $s l_{1}$ puesto 12 de acuerdo a que tan necesario

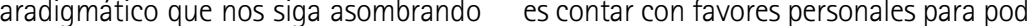

Cuando el senador Alejandro Guillier esa supuesta superioridad moral de nuestros ideres e instituciones respect vecindario sudamericano" (http://www. elmostrador.c//opinion/2015/03/06/ni-cocinas-ni-perdonazos), es un fiel reflejo que no somos tan pulcros, y que nos preocupamos que todo se vea bien en la superficie hemos sido mas "sutiles". El que el escándalo se vea más feo, con esposos, primos, sobrinos, hijos, etc., participando de estos turbios negocios demuestra que la sociedad chilees profunda No hay espacio para gue participen otros ni en los buenos ni en los malos negocios. Si volvemos al gráfico 1 , se ve que es justamente en los sectores peores evaluados por el público, donde más se repiten los apellidos y los lazos familiares.

La actual crisis puede ser una oportundad. Douglass Nort, (Nobel de Economía en el año 1993 por su aporte en el campo de la historia económica a través de análisis cuantitativo de la relación entre instituciones y las transformaciones economicas de los paises) al recibir su premio expres que "las instituciones son los limites ideados que estructuran la interacción humana. (reglas, leyes, constituciones), informales (normas de comportamiento, convenciones $y$ códigos autoimpuestos de conductal y sus características de aplicación Juntos definen la estructura de incentivos de las sociedades y especificamente de la econom Las instituciones y la tecnologia emplead determinan los costos de transacción transformación que se suman a los costos de producción

Chile ha destacado claramente en la generación de lo que Douglass describe como imitaciones formales, pero no logra realizar el cambio en las informales. Los ejemplos son variados en todos los ambitos: sistema de Alta didos de rencica con sus ada cambio de Gobierno; un sistema de compra píblica que en algunos casos genera sospechas por la cantidad enorme de requisitos a cumplir en poco tiempo $y$ que dejan con la sensación que alguien ya tien todo listo con información anticipada; ternas para cubrir puestos y la sospecha que y se fijaron los nombres; el uso de sociedades entre cónyuges simplemente para bajar

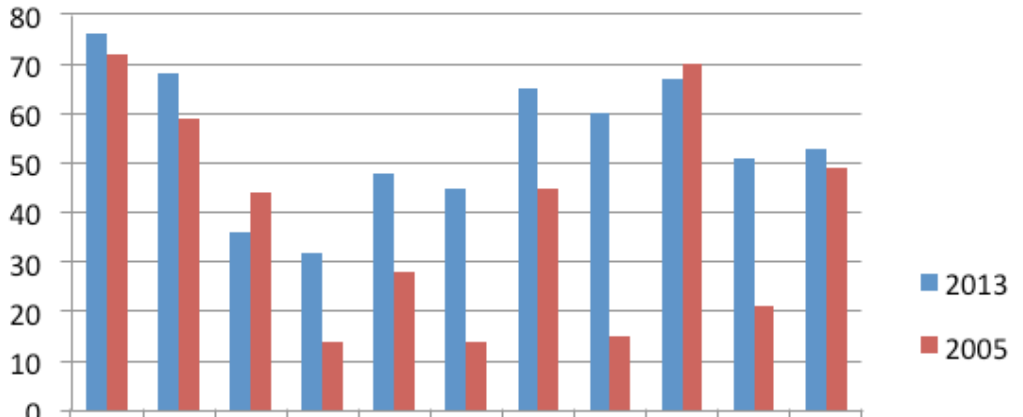

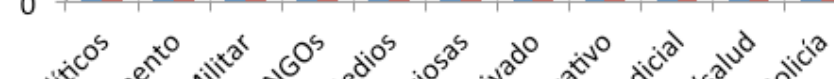
$b^{2 x^{2}}$ Grático 1.\% de Personas que cree que las siguientes instituciones son extremadamente corruptas muy corruptas. Años 2005 y 20

carga tributaria en la pareja; el respeto del financiamiento de campañas politicas en los sobre lo que se hace fuera de éminiencampaña l a falta de verdada baca de paso entre lo público y lo privado; un sistema de acreditación en educación en el que, incluso siendo legales, queda la sensación que los nombres importan y no los ntecedentes objetivos; el reparto informal (3 para el gobierno y 2 para la oposición) de consejeros del Banco Central (algo que lo está en la ley); la falta de regulación en poperación de los gremios empresariales, por nombrar solo algunos.

El paso al desarollo, no depende solamental nel formales de las que hablaba Douglass. Esas son las que operan microscópicamente, en términos marginales, carcomiendo los avances en productividad. La evasión en Transantiago nos debiera haber abierto los ojos mucho antes respecto a que, quizas y con similitud, en los casos actuales (en ámbitos distintos), no hemos sido capaces de generar esos códigos autoimpuestos de "trampa de los ingresos medios" 